\title{
Comorbidity and Pattern of Substance Use in Hospitalized Psychiatric Patients
}

\author{
Zahra Sepehrmanesh ${ }^{1}$; Afshin Ahmadvand ${ }^{1,3}$; Alireza Moraveji ${ }^{2}$ \\ ${ }^{1}$ Department of Psychiatry, Kashan University of Medical Sciences, Kashan, IR Iran \\ ${ }^{2}$ Department of Epidemiology, Kashan University of Medical Sciences, Kashan, IR Iran \\ *Corresponding Author: Afshin Ahmadvand, Department of Psychiatry, Kashan University of Medical Sciences, Kashan, IR Iran. Tel: +98-9131625987, E-mail: pschiatric.department@ \\ gmail.com
}

Received: April 5, 2014; Revised: May 15, 2014; Accepted: June 9, 2014

\begin{abstract}
Background: Substance use in patients with psychiatric disorder is an every-day seen. Detection of this comorbidity can significantly affect the treatment of these disorders, as well as substance use.

Objectives: This study has been conducted to determine the prevalence and pattern of substance use in hospitalized psychiatric patients. Patients and Methods: In this cross-sectional study, 210 hospitalized psychiatric patients were selected by simple randomization from all records of hospitalized patients. The instrument of gathering data was a demographic checklist including age, gender, marital status, education, type of disorder and substance abuse and duration of psychiatric disorder. Data were analyzed by SPSS version 16 using Fisher exact and Chi square tests.

Results: The mean age of patients was 37.9 years. Most of the patients were male, married and unemployed. The Prevalence of substance use was $36.7 \%$. The most prevalent pattern of substance use was opium, opioid, methamphetamines and other substances (poly substance). The prevalence of substance use in patients with mood disorders was more than the other disorders and the most prevalent substance use in these patients was opium and opioid. Poly substance use was the most prevalent pattern of use (80 \%) in psychotic and mood disorders due to substance. Significant difference was seen between genders, marital status, occupation, duration of illness and frequency of substance use $(\mathrm{P}<0.05)$, however no significant difference was seen between educational levels, age and substance use.

Conclusions: The patients with mood disorders had the highest comorbidity with substance use and concurrent use of poly substance was the most prevalent pattern of use in these patients. Therefore, successful treatment of psychiatric disorders and substance use needs multimodal and more serious interventions. Regarding to the pattern of poly substance use in these patients, careful screening should be performed at admission.
\end{abstract}

Keywords:Mental Disorders; Comorbidity; Substance-Related Disorders

\section{Background}

The prevalence of patients with dual diagnosis (comorbidity) suffering from a psychiatric disorder along with co-occurring substance use disorder are increasing through time. Response to treatment in patients with this comorbidity is difficult, regarding the high rate of recurrence and non-compliance to the treatment (1). Substance use in the society has reached an endemic proportion and psychiatric wards are required to reflect the arising issues. The psychiatric wards population is disproportionately younger in age, male dominant and are mostly socially disorganized (2). The Patients with severe psychotic disorder use substance more than the general population. Substance use disorders in these patients have negative consequences, including recurrence of disorder, repeated admissions, homelessness and violence. Therefore, this comorbidity is of high importance regarding to the high rate of dependency and abuse of substance and its effects on course of psychiatric disorders (3). These patients compared with patients who are using drugs merely put more pressure on their families and society (4). Using drugs such as Lysergic acid diethylamide (LSD), cannabis and amphetamines produce symptoms like schizophrenia that make diagnosis difficult $(5,6)$. Many mental disorders are associated with an increased risk of later substance use conditions (7). Three types of relations are discussed between substance use and psychosis:1-Substance use may lead to psychosis onset; therefore, either a cause or precipitant factor; 2-Substance use after onset of psychosis. 3-Substance use beginning concurrent with psychosis onset without affecting each other (8). The systemic review study of Le Bec et al. showed that there was a relationship between cannabis and psychosis onset and cannabis consumption may be as an independent risk factor of psychotic disorders (9). Dequardo study on substance use pattern among patients with schizophrenia showed that $20 \%$ of females and $48 \%$ of males had substance abuse and the most common substance was cannabis (28\%) following by alcohol (21\%) (10). Goswami study on the course of substance use of 22 patients with schizo-

Copyright (C) 2014, Iranian Red Crescent Medical Journal; Published by Kowsar Corp. This is an open-access article distributed under the terms of the Creative Commons Attribution License, which permits unrestricted use, distribution, and reproduction in any medium, provided the original work is properly cited. 
phrenia showed that 11 patients used opioids, 9 patients consumed alcohol, 5 patients consumed cannabis and three patients consumed several kinds of drugs simultaneously (11). Regier et al. reported that at least $20 \%$ of patients with severe and chronic psychiatric disorders had substance abuse history and 50\% of them had experienced substance use at least once during their lives. In this research, the prevalence of substance use in mood disorders, anxiety disorders, schizophrenia, personality disorders and other psychiatric disorders were 19.4\%, $11.9 \%, 27.5 \%, 42 \%$, and $14.7 \%$, respectively (12). Baigent pointed out that there is a relationship between drug self-medication to alleviate anxiety and a higher risk of anxiety disorders and at first, therapists should principally be aware to detect substance use in patients with anxiety and mood disorders. Furthermore, he stated that there was a relationship between chronic substance use and certain personality disorders (13). Hosseini study on comorbidity of substance use and psychiatric disorders in outpatients showed that $12.7 \%$ had current substance use and 3.3\% had recent substance use. Opium was the most common substance and mood disorders had the most comorbidity with substance abuse (14). The study of Ghaleiha in Hamadan on the patients hospitalized in psychiatric wards reported that about half of them had comorbidity with substance abuse (15).

\section{Objectives}

Considering the difference in prevalence of psychiatric disorders comorbidity and substance use in different societies and races (16), harms of substance to individual and society, the necessity of timely diagnosis of comorbid disorders and lack of study on patterns of substance abuse among patients in psychiatric hospitals in Iran, this study assessed the patterns and comorbidity of substance use in hospitalized psychiatric patients.

\section{Patients and Methods}

This is an analytical-cross sectional study. The statistical population of the research includes all the patients hospitalized in Kashan educational psychiatric hospital in 2013, Iran. The number of sample study was calculated 210 cases with consideration of $\mathrm{CI}=95 \%$, $\mathrm{P}=0.16$ (14) and $\mathrm{d}=0.05$. We used simple randomization according to the table of random numbers. The samples were selected randomly from nearly one thousand records of hospitalized patients in the psychiatric wards of Kashan University of Medical Sciences in 2013. Inclusion criteria were age over 18 years old, admission in the year 2013 at the mentioned psychiatric hospital. Exclusion criteria were mental retardation, delirium, dementia, mood disorders and psychotic disorders due to other medical condition.

\subsection{Tools}

Data collection tools consisted of a demographic check- list including age, gender, marital status, education, occupation, type of psychiatric disorders, type of substance and duration of disorder and substance use. Type of consuming substance was confirmed and determined by urine tests. Diagnostic records in this university hospital were written based on DSM-IV checklist. The Kappa Coefficient of this check list was 0.87 . The checklist was provided by Noorbala et al. based on DSM-IV criteria (14). This structural questionnaire includes 149 symptoms of mental disorders such as mood disorder, anxiety, psychotic, psychosomatic, epilepsy, mental retardation, and organic mental disorders. The data were analyzed by using SPSS version16 (IBM, USA) using descriptive statistics, Fisher exact and Chi-square tests.

\subsection{Ethical Consideration}

The study protocol was approved by Kashan University of Medical Sciences (March 14th 2013 with Code 29/801/ 5434). These results were extracted from the authors' MD degree thesis. Formal consent was obtained from hospital chief for using records. The records were used anonymously and all of the data were kept secret in this study.

\section{Results}

In this research, 210 patients' records were evaluated. The mean age was 37.9 years. The most patients in the psychiatric wards were male, married and unemployed. The prevalence of substance use was $36.7 \%$ in these patients, which $18.1 \%$ of them had more than one psychiatric disorder except substance use disorder (Table 1).

Table 1. Demographic Characteristics of Hospitalized Psychiatric Patients ${ }^{\text {a }}$

\begin{tabular}{|lc}
\hline Demographic Characteristics & Results, No. (\%) \\
\hline Age, $\mathbf{y}$ & $75(27.1)$ \\
$<30$ & $153(72.9)$ \\
\hline $30>$ & \\
\hline Gender & $132(62.9)$ \\
\hline Male & $78(37.1)$ \\
\hline Female & $16(7.6)$ \\
\hline Education & $178(84.8)$ \\
\hline Illiterate & $16(7.6)$ \\
\hline Less high school & \\
\hline Over high school & $77(36.7)$ \\
\hline Current Substance Use & $133(63.3)$ \\
\hline Yes & \\
\hline No & \\
\hline a Data are presented as No.(\%).
\end{tabular}


The most common psychiatric disorders among the hospitalized patients were mood disorders (52.9\%) mood and anxiety disorders (14.7\%), substance-induced psychotic disorder (11.9\%) and psychotic disorders (11.9\%), respectively (Figure 1).

Among patients who had substance abuse, 34 cases (44.2\%) had used one kind of substance only, while 43 (55.8\%) used more than one substance. Duration of substance use in $77.9 \%$ of patients was more than 5 years. Among those who were using substance less than 2 years, the most common substance was amphetamine compounds, while among those who were using substance for more than 2 years, poly substance use including opium, opioid and amphetamine compounds were more common. Overall, the most common pattern of substance use was opium with amphetamine and other substances (poly substances) in $55.8 \%$ patients (Figure 2 ). The highest rate of substance use was among the patients with mood disorders (42.8\%) comparing with other disorders. Opium and opioid was the most common substance among the patients with mood disorders, whereas, cannabis consumption was high among the patients with psychotic disorders. Consumption of several substances (poly substances) was the most common pattern of use among the patients with psychotic disorders due to substance and mood disorders due to substance (Table 2).

Substance use rate among patients over 30-year-old and less than 30-year-old patients were $39.2 \%$ and $29.8 \%$, respectively that this difference was not statistically significant. Female and male patients had a history of $11.5 \%$ and $51.5 \%$ substance use, respectively; significant statistically. By studying 'marital status', the divorced cases had the highest rate of substance use (66.7\%) following by single patient, with significant difference $(\mathrm{P}<0.05)$. The rate of substance use among cases with high school and secondary school degrees was $44.1 \%$ and the illiterate patients had lower substance use; but the difference was not statistically significant. Frequency of substance use among the unemployed patients (57\%) was higher than the employed patients and the difference was also statistically significant $(P=0.0001)$. Frequency of substance use among the patients whose disorder duration was less than one year was higher (54.1\%) than the patients whose duration of disorder was more than one year $(\mathrm{P}=$ 0.03 ) (Table 3).

In this study, significant difference was seen between gender, employment status, duration of disorder and marital status with substance use; whereas, statistically significant difference was not seen between age and educational level with substance use (Table 3).

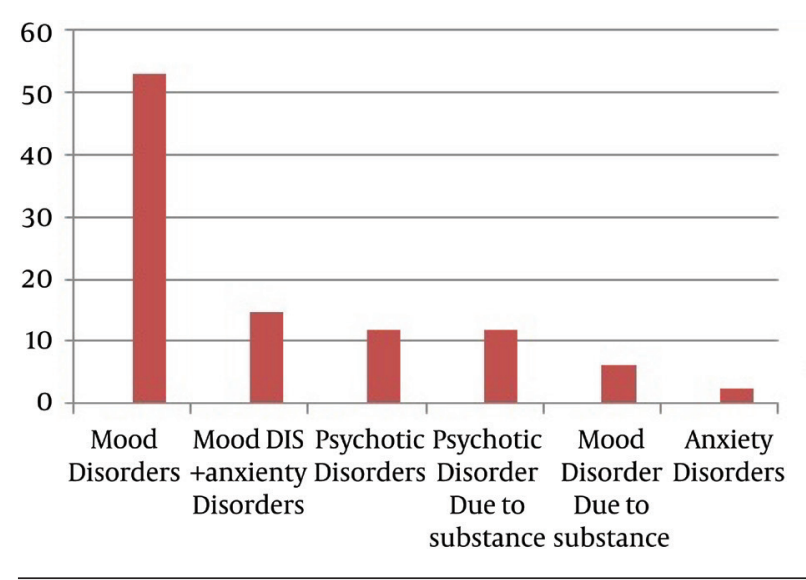

Figure 1. Frequency of Psychiatric Disorders in Hospitalized Patients



Figure 2. Frequency of Type of substance in Hospitalized Psychiatric Patients

Table 2. Prevalence of Substance Use in Patients With Comorbidity of Substance Use Disorder Based on type of Psychiatric Disorders and Substance

\begin{tabular}{|c|c|c|c|c|c|}
\hline Type of Substance & $\begin{array}{l}\text { Mood Disorder and } \\
\text { Anxiety Disorders }\end{array}$ & $\begin{array}{l}\text { Psychotic } \\
\text { Disorders }\end{array}$ & $\begin{array}{l}\text { Psychotic Disorders } \\
\text { Due to Substance }\end{array}$ & $\begin{array}{l}\text { Mood Disorders } \\
\text { Due to Substance }\end{array}$ & Total \\
\hline Opium and opioids & $15(48.4)$ & $3(37.5)$ & $3(12)$ & $0(0)$ & 21 \\
\hline Metamphetamines & $4(12.9)$ & $0(0)$ & $2(8)$ & $1(7.6)$ & 7 \\
\hline $\begin{array}{l}\text { Methamphetamines opium, } \\
\text { opioid, and other substance }\end{array}$ & $9(29)$ & $2(25)$ & $20(80)$ & $12(92.4)$ & 43 \\
\hline Cannabis & $3(9.7)$ & $3(37.5)$ & $0(0)$ & $0(0)$ & 6 \\
\hline Total & $31(100)$ & $8(100)$ & $25(100)$ & $13(100)$ & 77 \\
\hline
\end{tabular}


Sepehrmanesh Z et al.

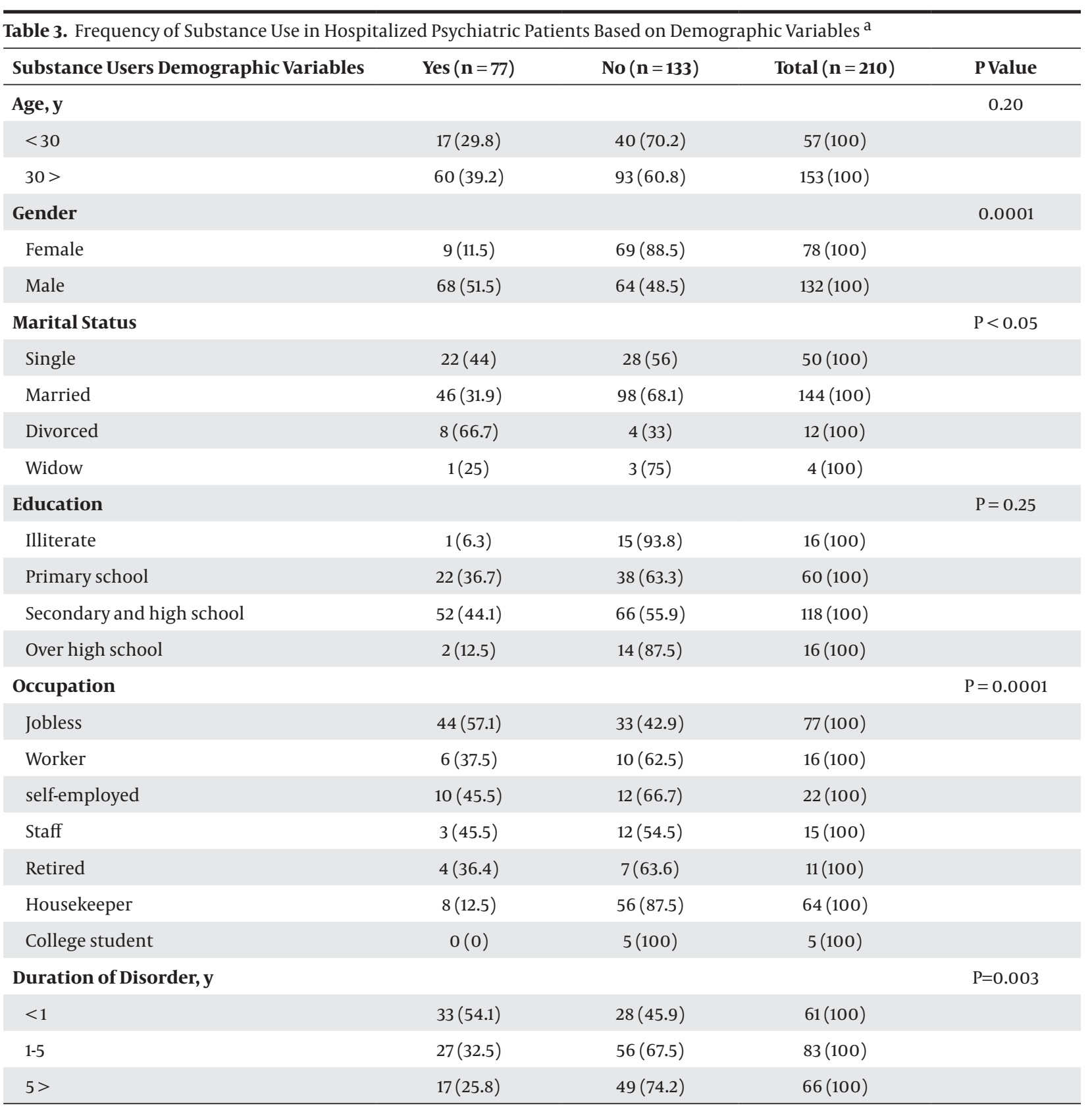

a Data are presented as No. (\%).

\section{Discussion}

This study was conducted to determine prevalence of comorbidity and pattern of substance abuse among hospitalized psychiatric patients in Kashan Psychiatric Hospital in 2013. The findings of the study showed that $36.7 \%$ of the patients had substance use comorbidity. The study of Ndetei in Kenya Psychiatric Hospital reported comorbidity of substance use and psychiatric disorders as $35 \%$, which is almost consistent with the present study (17). whereas, the prevalence of substance use in the study of Katz (19) and the study of Rodriguez et al. (18) in Spain were $24 \%$ and $24.9 \%$, respectively that these rates are lower than the rate of this study. Also, the rate of comorbidity of substance in the present study was higher than the study of Hosseini (14). The Prevalence of substance use in the studies of Hauli (21) in Tanzania among psychiatric patients, Sinclair (20) and Ghaleiha (15) in Hamadan were $68.5 \%, 74.8 \%$ and about $50 \%$, respectively, which are higher than the rates obtained in the present study. The differences in these prevalence demonstrated could be due to socioeconomic, cultural and geographical differences (22). In this study, 55.8\% of the patients who had substance use comorbidity used 
more than one type of substance. This rate is higher than Katz's study in Israel, which $28.2 \%$ of psychiatric patients had used more than two substances (19). In the present study, the most common pattern of substance use was opium, opioid compounds and other substances, which is consistent with the study of Hosseini and Ghaleiha in Iran. In these two studies, the most common substance was also opium $(14,15)$. Whereas, in the study of Hauli in Tanzania, alcohol was the most prevalent substance use. These results were inconsistent with our findings (23). Among patients with mood disorders, opium and opioid were the most common substances, while cannabis used most common by the psychotic patients. The study of Dequardo showed that Cannabis was the most used substance among psychotic patients, which is consistent with our findings (10). Ringen revealed that schizophrenic patients mostly used stimulants and non-alcoholics substance, and bipolar patients mostly used alcohol (24), which are inconsistent with the results of this study. This difference might be due to the religious and cultural differences. In Islam religion, which is the official religion of Iran, drinking alcohol is prohibited and prosecuted. Therefore, access to alcoholic drinks is highly unlikely impossible for patients. The results indicated that $80 \%$ the patients with substance-induced psychosis was due to use of several substances (poly substance use) that no research was found regarding this issue for comparison, which may be due to lack of new studies on the effects caused by stimulants, such as amphetamines and combination of substances on psychotic patients. The rate of substance use co-morbidly in male psychiatric patients was significantly higher than females in this study, which was consistent with the studies of Hauli et al. (21), Mueser et al. (3), Katz et al. (19), Rodriguez et al. (18), Hosseini et al. (14), and Ghaleiha et al. (15) that male psychiatric patients have a higher risk of substance use. According to this study, the rate of substance use comorbidity among the unemployed patients was higher than the others, which are inconsistent with Ghaleiha study in psychiatric hospital of Hamadan (15). This difference could be due to differences in sampling method. In Ghaleiha study sampling method was convenient; while in our study, sampling method was simple randomization. Regardless of the fact that the patients were unemployed prior to developing psychiatric disorders or their psychiatric disorder precedes unemployment, it should be noted that unemployment is a predisposing factor for psychiatric disorders, delinquency and addiction. Unemployed persons have lower level of social responsibility, sense of worthlessness and they usually have tendency to use of substance. In the present study divorced patients and single patients had the most prevalence of substance use comorbidity respectively, which was consistent with the studies of Hosseini, Katz and Mericle $(14,19,25)$, but inconsistent with the study of Hauli, which there was not significant relationship between marital status and substance use (21). Also in Behdani's study on substance use in schizophrenic patients, there was no significant relationship between marital status and substance use (23). The findings also showed that the patients whose duration of disorder was less than 1 year had the highest frequency of substance use comorbidity. It may be explained that the patients have higher tendency to substance use in the acute phase of disorders. As the findings of the study showed, there was a high prevalence of substance use comorbidity among the patients hospitalized in psychiatric wards and the most common pattern of substance use was poly substance use. Therefore, it is proposed to identify substance use carefully and appropriately in the beginning of the admission and this procedure should be added to the routine screening of these patients. With considering these circumstances, further attentions should be paid to combined and multimodal treatments such as medications, counseling, family therapy and social rehabilitation in order to achieve better outcomes.

\subsection{Limitation}

This research was done in one region. In addition, sometimes substance screening test may be false negative because interaction between substance and other drugs. Furthermore, having inclusion and exclusion criteria may limit generalization of the results. However, information necessary to diagnose a substance use disorder may not always have been available due to the nature of the patients' illnesses and thus limits the estimation of prevalence of these disorders.

\subsection{Strong Points}

This study has some strong point including detection of pattern and type of substance use among psychiatric inpatients which there is data limitation in this issue in recent years and in Iran no study find in this issue about pattern of sustance use in hospitalized patients at psychiatric wards. According to the research priorities in the field of substance use and recent epidemiological changes of substance including increase Metamphetamine, the present study addressed these topics.

\section{Acknowledgements}

We would like to express our thanks to Mrs Rezvan Saei for her unsparing cooperation in this survey.

\section{Authors' Contributions}

Study concept and design: Sepehrmanesh, Ahmadvand. Analysis and data interpretation: Moraveji and Sepehrmanesh. Drafting of the manuscript primary drafting: Ahmadvand and Sepehrmanesh. Critical revision of the manuscript for important intellectual content: Sepehrmanesh. Statistical analysis: Moraveji and Sepehrmanesh. 


\section{Funding/Supports}

This manuscript has been extracted from the MD degree thesis. The date of approval was 14 March 2013 with Code 29/801/5434.

\section{References}

1. Kavanagh DJ, McGrath J, Saunders JB, Dore G, Clark D. Substance misuse in patients with schizophrenia: epidemiology and management. Drugs. 2002;62(5):743-55.

2. Williams R, Cohen J. Substance use and misuse in psychiatric wards. A model task for clinical governance? Psychiatr Bull. 2000;24(2):43-6.

3. Mueser KT, Yarnold PR, Rosenberg SD, Swett CJ, Miles KM, Hill D. Substance use disorder in hospitalized severely mentally ill psychiatric patients: prevalence, correlates, and subgroups. Schizophr Bull. 2000;26(1):179-92.

4. Siris SG. Pharmacological treatment of substance-abusing schizophrenic patients. Schizophr Bull.1990;16(1):111-22.

5. Linszen DH, Dingemans PM, Lenior ME. Cannabis abuse and the course of recent-onset schizophrenic disorders. Arch Gen Psychiatry. 1994;51(4):273-9.

6. Sato M, Numachi Y, Hamamura T. Relapse of paranoid psychotic state in methamphetamine model of schizophrenia. Schizophr Bull. 1992;18(1):115-22.

7. Swendsen J, Conway KP, Degenhardt L, Glantz M, Jin R, Merikangas KR, et al. Mental disorders as risk factors for substance use, abuse and dependence: results from the 10-year follow-up of the National Comorbidity Survey. Addiction. 2010;105(6):1117-28.

8. Turner WM, Tsuang MT. Impact of substance abuse on the course and outcome of schizophrenia. Schizophr Bull.1990;16(1):87-95.

9. Le Bec PY, Fatseas M, Denis C, Lavie E, Auriacombe M. [Cannabis and psychosis: search of a causal link through a critical and systematic review]. Encephale. 2009;35(4):377-85.

10. DeQuardo JR, Carpenter CF, Tandon R. Patterns of substance abuse in schizophrenia: nature and significance. J Psychiatr Res. 1994;28(3):267-75.

11. Goswami S, Singh G, Mattoo SK, Basu D. Courses of substance use and schizophrenia in the dual-diagnosis patients: is there a relationship? Indian J Med Sci. 2003;57(8):338-46.

12. Regier DA, Farmer ME, Rae DS, Locke BZ, Keith SJ, Judd LL, et al. Comorbidity of mental disorders with alcohol and other drug abuse. Results from the Epidemiologic Catchment Area (ECA) Study. JAMA. 1990;264(19):2511-8.

13. Baigent M. Managing patients with dual diagnosis in psychiatric practice. Curr Opin Psychiatry. 2012;25(3):201-5.

14. Hosseini SH, Zarghami M, Mousavi SE, Nateghi GHR, Masuod Zadeh A. Study on the simultaneity of the substance abuse with psychiatric disorder in referred of psychiatry clinic of Zare hospital for period of one year. J Mazandaran Univ Med Sci. 2008;18(67):67-74.

15. Ghaleiha A, Zarabian MK, Haghighi M, Bahrami MH. Frequency of substance abuse in hospitalized patients in psychiatric wards of Frshchian hospital in Hamedan. J Hamedan Univ Med Sci. 2010;17(1-55):52-7.

16. Smith SM, Stinson FS, Dawson DA, Goldstein R, Huang B, Grant $\mathrm{BF}$. Race/ethnic differences in the prevalence and co-occurrence of substance use disorders and independent mood and anxiety disorders: Results from the National Epidemiologic Survey on Alcohol and Related Conditions. Psychol Med. 2006;36(7):987-98.

17. Ndetei DM, Pizzo M, Kuria MW, Khasakhala L, Maru MH, Mutiso V. Substance abuse and psychiatric co-morbidities: a case study of patients at Mathari Psychiatric Hospital, Nairobi, Kenya. Afr Drug Alcohol Stud. 2008;7(1)

18. Rodriguez-Jimenez R, Aragues M, Jimenez-Arriero MA, Ponce G, Munoz A, Bagney A, et al. [Dual diagnosis in psychiatric inpatients: prevalence and general characteristics]. Invest Clin. 2008;49(2):195-205.

19. Katz G, Durst R, Shufman E, Bar-Hamburger R, Grunhaus L. Substance abuse in hospitalized psychiatric patients. Isr Med Assoc J. 2008;10(10):672-5.

20. Sinclair JM, Latifi AH, Latifi AW. Co-morbid substance misuse in psychiatric patients: prevalence and association with length of inpatient stay. J Psychopharmacol. 2008;22(1):92-9.

21. Hauli KA, Ndetei DM, Jande MB, Kabangila R. The prevalence of substance use among psychiatric patients: the case study of Bugando Medical centre, Mwanza (northern Tanzania). Subst Abus 2011;32(4):238-41.

22. Drake RE, Wallach MA, Alverson HS, Mueser KT. Psychosocial as pects of substance abuse by clients with severe mental illness. $J$ Nerv Ment Dis. 2002;190(2):100-6.

23. Behdani F, Hebrani P. Substance use in schizophrenic patient admitted in Ibn-e Sina Hospital‘Mashhad. Q J Fund Ment Health. 2008;10(36):93-70

24. Ringen PA, Lagerberg TV, Birkenaes AB, Engn J, Faerden A, Jonsdottir $\mathrm{H}$, et al. Differences in prevalence and patterns of substance use in schizophrenia and bipolar disorder. Psychol Med. 2008;38(9):1241-9.

25. Mericle AA, Ta Park VM, Holck P, Arria AM. Prevalence, patterns, and correlates of co-occurring substance use and mental disorders in the United States: variations by race/ethnicity. Compr Psychiatry. 2012;53(6):657-65 